\title{
Proteasomes in Lungs From Organ Donors and Patients With End- Stage Pulmonary Diseases
}

\author{
T. A. BAKER ${ }^{1}$, H. H. BACH IV ${ }^{1,2}$, R. L. GAMELLI ${ }^{1}$, R. B. LOVE ${ }^{3,4}$, M. MAJETSCHAK ${ }^{1,2}$ \\ ${ }^{1}$ Department of Surgery, Burn and Shock Trauma Research Institute, Loyola University Chicago, \\ Maywood, IL, USA, ${ }^{2}$ Department of Molecular Pharmacology and Therapeutics, Loyola University \\ Chicago, Maywood, IL, USA, ${ }^{3}$ Department of Thoracic and Cardiovascular Surgery, Loyola \\ University Chicago, Maywood, IL, USA, ${ }^{4}$ Department of Surgery, Medical College of Wisconsin, \\ Milwaukee, USA
}

Received July 5, 2013

Accepted October 17, 2013

On-line February 24, 2014

\section{Summary}

Proteasomes appear to be involved in the pathophysiology of various acute and chronic lung diseases. Information on the human lung proteasome in health and disease, however, is sparse. Therefore, we studied whether end-stage pulmonary diseases are associated with alterations in lung 20S/26S proteasome content, activity and 20S subunit composition. Biopsies were obtained from donor lungs $(n=7)$ and explanted lungs from patients undergoing lung transplantation because of end stage chronic obstructive pulmonary disease (COPD; $n=7$ ), idiopathic pulmonary fibrosis (IPF, $n=7$ ) and pulmonary sarcoidosis $(n=5) .20 S / 26 S$ proteasomes in lung extracts were quantified by ELISA, chymotrypsin-like proteasome peptidase activities measured and $20 \mathrm{~S}$ proteasome $\beta$ subunits analyzed by Western blot. As compared with donor lungs, proteasome content was increased in IPF and sarcoidosis, but not in COPD. The relative distribution of free $20 \mathrm{~S}$ and $26 \mathrm{~S}$ proteasomes was similar; $20 \mathrm{~S}$ proteasome was predominant in all extracts. Proteasome peptidase activities in donor and diseased lungs were indistinguishable. All extracts contained a mixed composition of inducible 20S $\beta$ immuno-subunits and their constitutive counterparts; a disease associated distribution could not be identified. A higher content of lung proteasomes in IPF and pulmonary sarcoidosis may contribute to the pathophysiology of human fibrotic lung diseases.

\section{Key words}

$20 \mathrm{~S}$ proteasome - $26 \mathrm{~S}$ proteasome - Chronic obstructive pulmonary disease - Idiopathic pulmonary fibrosis • Pulmonary sarcoidosis

\section{Corresponding author}

Matthias Majetschak, Loyola University Chicago, 2160 S. $1^{\text {st }}$ Avenue, Maywood, IL 60153, USA. Fax: (708) 327-2813. E-mail: mmajetschak@luc.edu

\section{Introduction}

Proteasomes are important proteolytic machineries in all eukaryotic cells and among the major proteolytic systems that contribute to protein quality control (Orlowski 1990, Baumeister et al. 1998, Hershko and Ciechanover 1998, Groll and Huber 2004). Proteasomes consist of a cylinder-shaped protein complex (20S core particle, 20S) which can be capped at each end by a $19 \mathrm{~S}$ regulator complex when $\mathrm{ATP} / \mathrm{Mg}^{2+}$ is present and is then termed $26 \mathrm{~S}$ proteasome $(26 \mathrm{~S})$. The $20 \mathrm{~S}$ core particle is composed of four stacked rings. Each ring consists of $7 \alpha$ - and $\beta$-type subunits $\left(\alpha_{1-7} \beta_{1-7} \beta_{1-7} \alpha_{1-7}\right)$. In eukaryotic $20 \mathrm{~S}$ core particles, the proteolytic active sites are located in the subunits $\beta 1, \beta 2$ and $\beta 5$ of the inner rings. These subunits can be replaced by inducible subunits $\beta 1 \mathrm{i}, \beta 2 \mathrm{i}$ and $\beta 5 \mathrm{i}$. As two of these subunits are encoded within the MHC class II region, they are referred to as immuno-(i)-subunits (Rock and Goldberg 1999, Groll and Huber 2004, Gomes et al. 2006, Gallastegui and Groll 2010, Guillaume et al. 2010, Sijts and Kloetzel 2011). Whereas proteins that have been covalently modified with ubiquitin are substrates for $\mathrm{ATP} / \mathrm{Mg}^{2+}$ dependent degradation by the $26 \mathrm{~S}$ proteasome, the $20 \mathrm{~S}$ core particle alone contributes to the removal of 
misfolded and damaged proteins, independent of $\mathrm{ATP} / \mathrm{Mg}^{2+}$ or ubiquitylation (Eytan et al. 1993, Orlowski and Wilk 2003).

Several lines of evidence suggest that proteasomes are involved in the pathophysiology of various acute and chronic lung diseases. Besides their involvement in the pathophysiology of lung cancer and pulmonary inflammation, proteasomal dysfunction is thought to contribute to proteostasis imbalance in chronic obstructive lung disease (COPD) and idiopathic pulmonary fibrosis (IPF) (Bunn 2004, Malhotra et al. 2009, Weiss et al. 2010, Bodas et al. 2012, Zhao et al. 2012).

Curative treatment strategies for COPD, IPF or pulmonary sarcoidosis are currently not available and lung transplantation is the only treatment option for many patients with advanced disease. Thus, a better understanding of the regulation of the proteasome in normal and diseased lungs is essential to assess its role in pulmonary pathophysiology and as a possible drug target. Information on the human lung proteasome in health and disease, however, is sparse. Therefore, it was the aim of this pilot study to determine whether end-stage pulmonary diseases are associated with alterations in lung 20S/26S proteasome content, activity and 20S subunit composition.

\section{Materials and Methods}

\section{Lung biopsies}

This study was approved by the Institutional Review Board and informed consent was obtained for the use of the lung biopsies. Lung biopsies were obtained from discarded donor lungs that fulfilled transplantation criteria ( $n=7$, age: $56 \pm 27$ years, 3/1/3 male/female/ unknown) and from explanted lungs from patients undergoing single or double lung transplantation because of end stage COPD ( $n=7$, age: $64 \pm 6$ years, $6 / 1$ male/female), IPF ( $n=7$, age: $67 \pm 5$ years, $5 / 2$ male/female) or sarcoidosis $(n=5,1 / 4$ male/female, age: $51 \pm 4$ years). Sixteen of the transplanted patients were of Caucasian origin, one patient with sarcoidosis was of African-American origin and one patient with IPF was of Hispanic origin. The diagnosis was confirmed by histology in all transplanted patients. Biopsies were snap frozen in liquid nitrogen immediately after resection and stored at $-70{ }^{\circ} \mathrm{C}$ until further processing.

\section{Tissue processing}

Snap frozen tissues were homogenized in $1 / 10$ phosphate buffered saline, $2 \mathrm{mM} \mathrm{ATP,} 5 \mathrm{mM} \mathrm{MgCl}_{2}$, pH 7.4 (1:5 weight/volume), centrifuged $\left(16,600 \mathrm{~g}, 4{ }^{\circ} \mathrm{C}\right.$, $30 \mathrm{~min}$ ) and supernatants (= extracts) aliquoted, as described (Majetschak et al. 2008a, Geng et al. 2009). All measurements in tissue extracts were standardized to total protein content (Lowry et al. 1951) and are reported per $\mathrm{mg}$ of protein.

\section{Proteasome enzyme linked immunosorbent assays (ELISA)}

The concentration of total 20S proteasomes (free $20 \mathrm{~S}$ core particles and $20 \mathrm{~S}$ core particles within the $26 \mathrm{~S}$ proteasome complex) and $26 \mathrm{~S}$ proteasomes in lung extracts was quantified as described in detail previously (Majetschak and Sorell 2008). For the calculation of the molar concentration of $20 \mathrm{~S}$ core particles, a molecular mass of $700 \mathrm{kDa}$ was used. For the $26 \mathrm{~S}$ proteasome complex, a molecular mass of 1.7 MDa was assumed to account for a mixture of $20 \mathrm{~S}$ core complexes that are capped with either one or two $19 \mathrm{~S}$ regulator complexes. The concentration of free $20 \mathrm{~S}$ proteasomes was calculated as concentration of total $20 \mathrm{~S}$ proteasomes minus the concentration of $26 \mathrm{~S}$ proteasome complexes.

\section{Proteasome peptidase activity assay}

Proteasome peptidase activities $(=$ total peptidase activity minus activity in the presence of epoxomicin) in lung extracts were measured employing the fluorogenic peptide substrate $N$-Suc-Leu-Leu-ValTyr-7-amino-4-methylcoumarin (chymotryptic-like, CTL, Biomol), as described (Majetschak et al. 2008a, Geng et al. 2009, Baker et al. 2010). Reaction mixtures contained $1 \mathrm{mmol} / \mathrm{l}$ DTE, $2 \mathrm{mmol} / \mathrm{l}$ ATP, $5 \mathrm{mmol} / \mathrm{l}$ $\mathrm{MgCl}_{2}, 10 \mathrm{mmol} / \mathrm{l}$ Tris/HCl, pH 8.0, $200 \mu \mathrm{mol} / \mathrm{l}$ peptide substrate $(0-400 \mu \mathrm{mol} / 1$ peptide substrate for the measurement of the substrate dependency) and $0.5 \mathrm{mg} / \mathrm{ml}$ tissue extract. All enzyme assays were performed immediately after preparation of the lung extracts to prevent from proteasome inactivation by freeze-thawing.

\section{Western blots}

Western blotting with anti-proteasome core (anti- $\alpha 5,7, \beta 1,5,5 \mathrm{i}, 7), \beta$ subunit specific antibodies ( $\beta 1-7$, $\beta 1 \mathrm{i}, \beta 2 \mathrm{i}, \beta 5 \mathrm{i})$ and densitometric quantification of the chemiluminescence signals was performed as described (Majetschak et al. 2008a, Geng et al. 2009). All antibodies were obtained from Enzo. Chemiluminescence signals were detected with a Chemidoc imaging system and analyzed using the Quantity One gel analyses 
software (BioRad). Human erythrocyte 20S proteasome (Boston Biochem) was used as a standard.

\section{Analytical gel filtration}

Analytical gel filtration was performed on a Superose 6-column (GE Healthcare) in $25 \mathrm{mmol} / \mathrm{l}$ Tris/HCl, $\mathrm{pH} 7.5,150 \mathrm{mmol} / \mathrm{l} \mathrm{NaCl}, 2 \mathrm{mmol} / \mathrm{l}$ ATP, $5 \mathrm{mmol} / 1 \mathrm{Mg}^{2+}$ at $5{ }^{\circ} \mathrm{C}$ using the DuoFLowchromatography system (Bio-Rad). The flow rate was $0.25 \mathrm{ml} / \mathrm{min}$ and fractions of $0.5 \mathrm{ml}$ were collected. The column was calibrated using proteins of known molecular mass (thyroglobulin $(670 \mathrm{kDa})$, bovine $\gamma$-globulin
$(158 \mathrm{kDa})$, chicken ovalbumin $(44 \mathrm{kDa})$, equine myoglobin (17kDa) (all from Bio-Rad)).

\section{Statistics}

Data are described as mean $\pm \mathrm{SD}$. One-way analysis of variance with Dunnett's multiple comparison test to control for multiple testing were used to compare differences between groups. Statistical analyses and nonlinear regression analyses were calculated with the GraphPad-Prism program (GraphPad-Software). A twotailed $\mathrm{p}<0.05$ was considered significant.
A

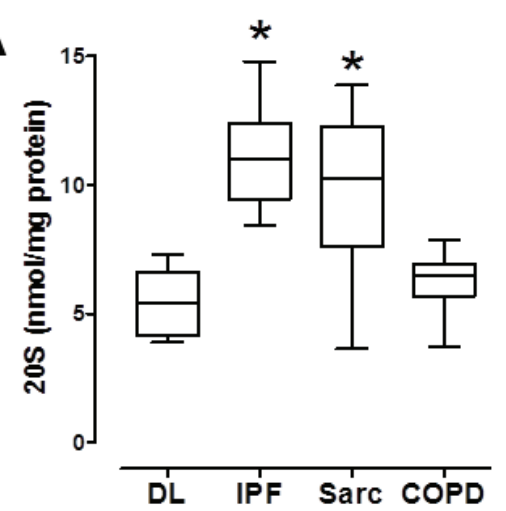

C

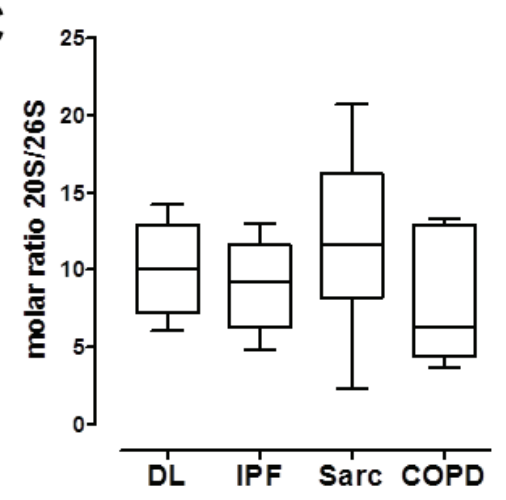

B

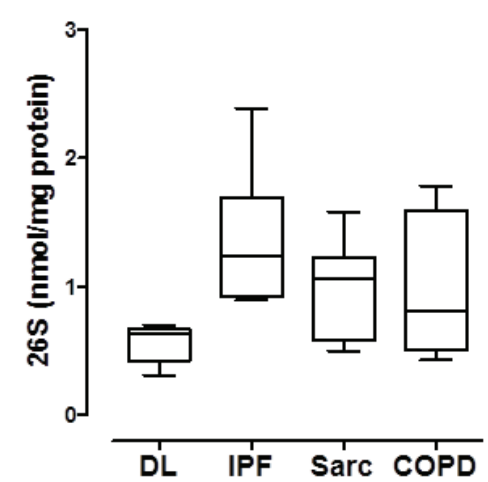

D

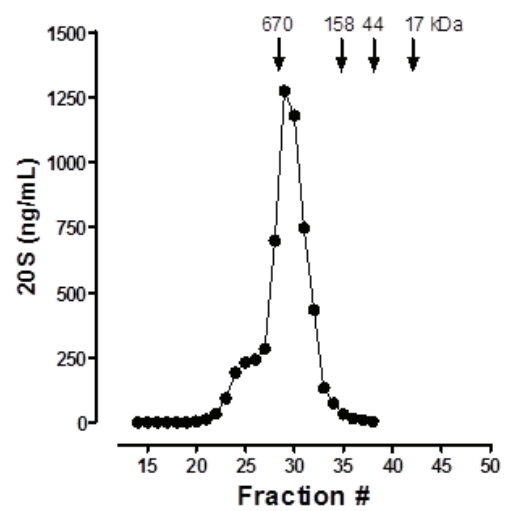

Fig. 1. Proteasome content in human lung extracts. DL: donor lung. IPF: idiopathic pulmonary fibrosis. COPD: chronic obstructive pulmonary disease. Sarc: sarcoidosis. RFU: relative fluorescence units. Boxes extend from the $25^{\text {th }}$ to $75^{\text {th }}$ percentile, the horizontal line and error bars show the median, minimum and maximum. *: $\mathrm{p}<0.05$ vs. DL. A. $20 \mathrm{~S} / \mathrm{mg}, \mathrm{n}=5-7 /$ group. B. $26 \mathrm{~S} / \mathrm{mg}$, $\mathrm{n}=5-7 /$ group. C. molar 20S/26S ratio, $\mathrm{n}=5-7 /$ group. D. A donor lung extract $(0.5 \mathrm{ml})$ was separated on a Superose 6 column. The $20 \mathrm{~S}$ concentrations in the eluted fractions were quantified by enzyme linked immunosorbent assay. The arrows show the elution positions of proteins with known molecular masses.

\section{Results}

\section{Proteasome content}

The content of total 20S proteasomes in donor lung extracts was $4.1 \pm 0.9 \mu \mathrm{g} / \mathrm{mg}$. As compared with the total $20 \mathrm{~S}$ content, the amount of $26 \mathrm{~S}$ proteasome complexes in donor lung extracts was 4-fold lower $(0.96 \pm 0.23 \mu \mathrm{g} / \mathrm{mg})$. The molar ratio between free $20 \mathrm{~S}$ core particles and $26 \mathrm{~S}$ complexes was $10 \pm 3$. As compared with donor lungs (molar 20S content: $5.4 \pm 1.3$ $\mathrm{pmol} / \mathrm{mg}$ ), the content of free $20 \mathrm{~S}$ proteasomes per mg of protein was similar in extracts from patients with COPD
$(6.2 \pm 1.3 \mathrm{pmol} / \mathrm{mg})$ and significantly increased in lung extracts from patients with IPF $(11.1 \pm 2.2 \mathrm{pmol} / \mathrm{mg})$ and sarcoidosis $(9.8 \pm 3.4 \mathrm{pmol} / \mathrm{mg}$; Fig. 1A). Whereas quantification of the $26 \mathrm{~S}$ content showed a similar tendency, these differences did not reach statistical significance (Fig. 1B). The molar ratios between $20 \mathrm{~S}$ and $26 \mathrm{~S}$ proteasomes in lung extracts were similar in all groups (molar 20S/26S ratio: donor lungs - 10.0 \pm 3.1 ; IPF

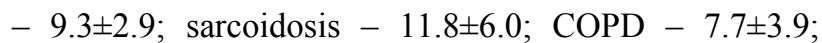
$\mathrm{p}>0.05$; Fig. 1C). To confirm the relative distribution of $20 \mathrm{~S}$ and $26 \mathrm{~S}$ proteasomes, we then performed gel filtration experiments with donor lung extracts (Fig. 1D). 
Consistent with the molar 20S/26S ratio that we determined by ELISA, $90 \%$ of 20 S proteasomes in donor lung extracts eluted in fractions that corresponded to a molecular mass of $700 \mathrm{kDa}$ (fractions \#27-33), whereas only $10 \%$ of $20 \mathrm{~S}$ proteasomes were detectable at elution positions corresponding to a molecular mass of $>1 \mathrm{MDa}$ (fractions \#23-26).
A

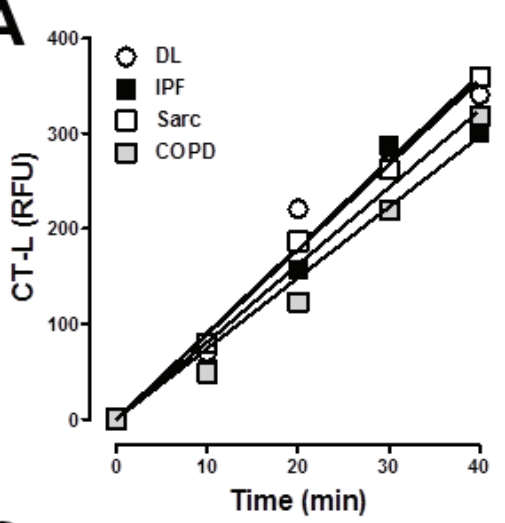

C

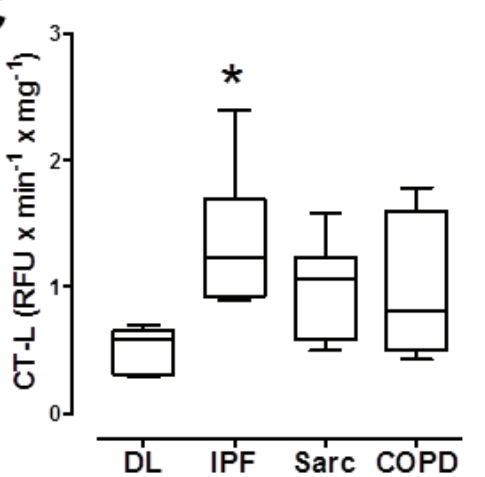

B

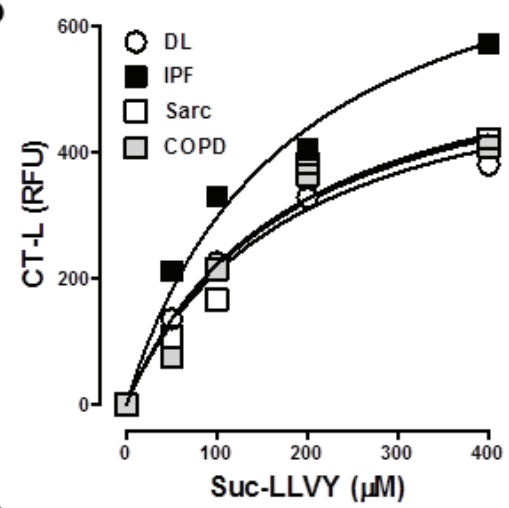

D

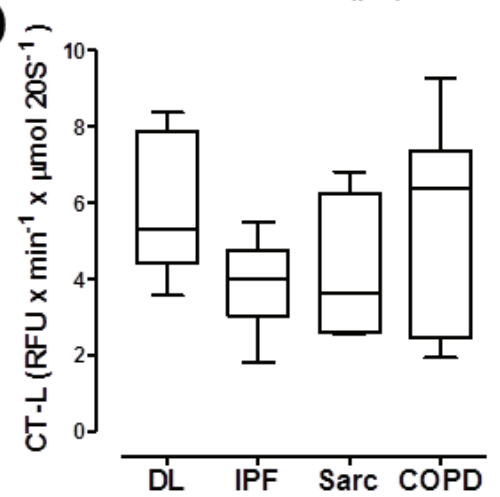

Fig. 2. Proteasome peptidase activities in human lung extracts. DL: donor lung. IPF: idiopathic pulmonary fibrosis. COPD: chronic obstructive pulmonary disease. Sarc: sarcoidosis. RFU: relative fluorescence units. Boxes extend from the $25^{\text {th }}$ to $75^{\text {th }}$ percentile, the horizontal line and error bars show the median, minimum and maximum. *: $p<0.05$ vs. DL. A. Time progression of the chymotrypsin-like proteasome peptidase activity (CT-L). B. Substrate dependency of the CT-L. C. CT-L/mg, $n=5-7 /$ group. D. CT-L/mol 20S, $n=5-$ 7/group. E. Epoxomicin sensitivity of the $C T-L$ in $\% \quad(100 \%=$ no epoxomicin; $0 \%=7 \mu \mathrm{M}$ epoxomicin), $\mathrm{n}=3$ /group, mean \pm SD.

E

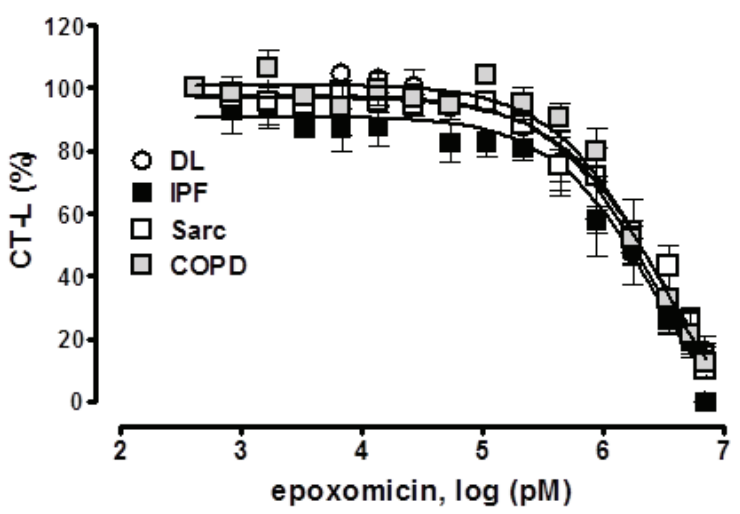

\section{Proteasome peptidase activity}

Next, we determined the time progression and substrate dependency of the proteasome peptidase activity in the lung extracts. We observed linear enzyme kinetics over $40 \mathrm{~min}$ in extracts from donor and diseased lungs (Fig. 2A). The substrate dependency of the proteasome peptidase activity for the chymotrypsin-like peptide substrate showed Michaelis-Menten kinetics. The Michaelis constant $(\mathrm{Km})$ was similar in all extracts $(\mathrm{Km}$ for Suc-LLVY: donor lungs - 126 $\pm 17 \mu \mathrm{M}$, IPF - 134 \pm 30 $\mu \mathrm{M}$, Sarc $-247 \pm 138 \mu \mathrm{M}, \mathrm{COPD}-218 \pm 148 \mu \mathrm{M} ; \mathrm{r}^{2}: 0.83-$ 0.99 ; $>0.05$; Fig. 2B).

As expected based on the quantification of the proteasome content in the lung extracts, chymotrypsinlike proteasome peptidase activity was significantly increased in lung extracts from IPF patients when the enzyme activity was expressed per mg of total extract protein (Fig. 2C). There were no differences among the 
lung extracts, however, when the specific proteasome peptidase activity was expressed per mol of $20 \mathrm{~S}$ proteasome, which contains the catalytically active sites (Fig. 2D).

To further characterize the enzymatic properties of the lung proteasome, we tested the sensitivity of the proteasome peptidase activity in lung extracts to the specific proteasome inhibitor epoxomicin (Meng et al. 1999). We detected similar inhibition kinetics in extracts from donor lungs and diseased lungs $\left(\operatorname{LogIC} \mathrm{I}_{50}\right.$ : 6.3-6.6, $\mathrm{p}>0.05$; Fig. 2E).

\section{Proteasome subunit composition}

To assess the subunit composition of donor and diseased lungs, we first analyzed lung extracts by Western blotting utilizing an antibody against multiple $\alpha$ and $\beta$ 20S subunits (Fig. 3). Purified human erythrocyte $20 \mathrm{~S}$ proteasome was used for comparison because it does not contain inducible immuno-subunits (Claverol et al. 2002, Chen et al. 2009). In contrast to erythrocyte proteasomes in which two bands were detectable, this antibody recognized four major bands in all lung extracts (Fig. 3A/B), suggesting differences in the subunit composition between erythrocyte and lung $20 \mathrm{~S}$ proteasomes. We then analyzed the expression of constitutive and inducible $20 \mathrm{~S}$ proteasome $\beta$ subunits by Western blotting with subunit specific antibodies (Fig. 4). Donor lung extracts contained all constitutive ( $\beta 1-7)$ and immuno ( $\beta 1 \mathrm{i}, \beta 2 \mathrm{i}, \beta 5 \mathrm{i})$ subunits (Fig. 4A-D). All immuno-subunits and their constitutive counterparts were also detectable in extracts from diseased lungs, whereas immuno-subunits were not detectable in human erythrocyte $20 \mathrm{~S}$ proteasomes (Fig. 4A-E). When membranes with lung extracts that showed obvious differences in the band intensities for the subunits $\beta 1, \beta 2$ or $\beta 5$ were re-probed for the corresponding inducible immuno-subunits, we observed an inverse relationship of the band intensities, and vice versa (Fig. 4E). As shown in Figure 4E for lung extracts from patients with COPD, the chemiluminescence signals for the bands corresponding to the immuno-subunits and their corresponding counterparts in donor lung extracts and extracts from diseased lungs varied considerably and did not provide evidence for a disease associated pattern by Western blotting.

A

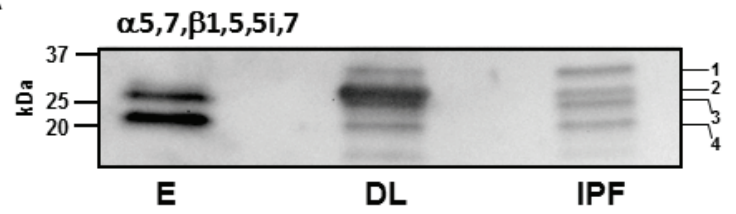

B

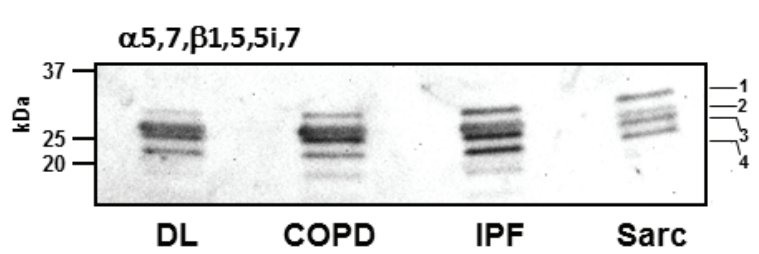

Fig. 3. $20 \mathrm{~S}$ proteasome core subunits $(a 5,7, \beta 1,5,5 i, 7)$ in human lung extracts. Western blots with anti-proteasome core $(a 5,7, \beta 1,5,5 i, 7)$. Each lane contains 300 pmol of $20 \mathrm{~S}$ proteasomes. The migration positions of molecular mass standards are indicated. A. E: human erythrocyte $20 \mathrm{~S}$ proteasome. DL: donor lung. IPF: idiopathic pulmonary fibrosis. B. DL: donor lung. COPD: chronic obstructive pulmonary disease. IPF: idiopathic pulmonary fibrosis. Sarc: sarcoidosis.

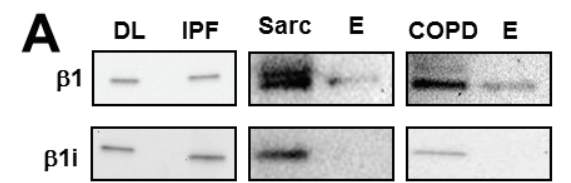

B

$$
\beta 2
$$

$\beta 2 \mathbf{i}$
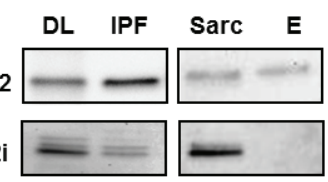

COPD DL

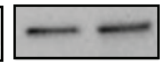

D
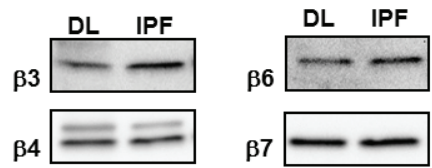

C

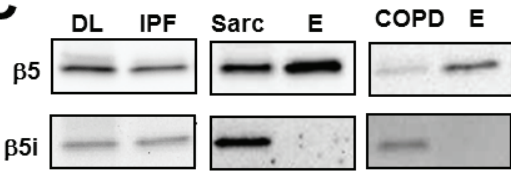

$\beta 4$

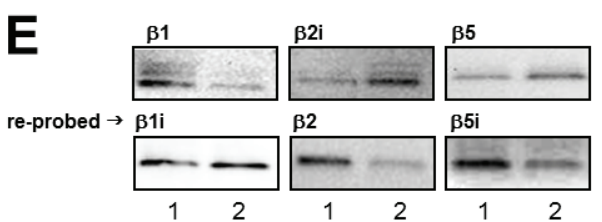

Fig. 4. Constitutive and inducible $20 \mathrm{~S}$ proteasome $\beta$ subunits in human lung extracts. E: human erythrocyte $20 \mathrm{~S}$ proteasome. DL: donor lung. IPF: idiopathic pulmonary fibrosis. COPD: chronic obstructive pulmonary disease. Sarc: sarcoidosis. Each lane contains $300 \mathrm{pmol}$ of $20 \mathrm{~S}$ proteasomes. A. Western blots with anti- $\beta 1$ and anti- $\beta 1 i$. B. Western blots with anti- $\beta 2$ and anti- $\beta 2$ i. C. Western blots with anti- $\beta 5$ and anti- $\beta 5$ i. D. Western blots with anti- $\beta 3,4,6,7$. E. Top: Western blots with anti- $\beta 1$, anti- $\beta 2 \mathrm{i}$ and anti- $\beta 5$. Bottom: Membranes were stripped and reprobed with antibodies against the corresponding inducible or constitutive counterparts, as indicated. Lanes 1 and 2 contain lung extracts from two different patients with COPD. 


\section{Discussion}

In the present pilot study, we detected that proteasome content in lung extracts from patients with IPF and pulmonary sarcoidosis was increased, as compared to that in lung extracts from organ donors and patients with COPD. The relative distribution between $20 \mathrm{~S}$ and 26S proteasomes was similar and proteasome peptidase activities were indistinguishable in donor and diseased lungs. All lung extracts contained a mixed composition of inducible $20 \mathrm{~S} \beta$ immuno-subunits and their constitutive counterparts. Disease associated alterations in $20 \mathrm{~S}$ proteasome subunit distribution, however, could not be identified.

The amount of $20 \mathrm{~S}$ proteasomes that we determined in donor lungs is in agreement with the cellular 20S content that has been estimated based on Western blot analyses in human embryonic pulmonary epithelial cells (L132; 6.9 $2.8 \mu \mathrm{g} / \mathrm{mg}$ ) (Brooks et al. 2000). A several fold excess of $20 \mathrm{~S}$ over $26 \mathrm{~S}$ proteasomes has been reported in rat liver and L132 cells previously (Brooks et al. 2000). Along with our finding that the molar $20 \mathrm{~S} / 26 \mathrm{~S}$ proteasome ratio is approximately 10 in human lung extracts, these data suggest that the free $20 \mathrm{~S}$ is predominant in solid organs. Our findings suggest that IPF and, to a lesser extent, sarcoidosis are associated with increased expression of lung proteasomes in which the physiological equilibrium between $20 \mathrm{~S}$ and $26 \mathrm{~S}$ proteasomes is maintained. It should be noted, however, that quantification of proteasome content per $\mathrm{mg}$ of protein likely underestimates proteasome content in lungs from patients with IPF and sarcoidosis, because in both diseases the fibrotic remodeling will lead to an increased protein content of the homogenates.

Whereas the human lung proteasome in patients with IPF and sarcoidosis has not been studied previously, reduced lung proteasome peptidase activity per $\mathrm{mg}$ of protein has been described in patients with COPD (Malhotra et al. 2009). In this study, however, proteasome peptidase activity was tested after sodium dodecyl sulfate (SDS) activation of a proteasome fraction that was enriched using a ubiquitin-like (UbL) domain linked to affinity matrix beads (Malhotra et al. 2009). Although this observation may suggest changes in substrate recognition by the proteasome (Tanaka et al. 1989, Dahlmann et al. 1993), information on the enzymatic activity of proteasomes without SDS activation has not been provided (Malhotra et al. 2009).
Thus, these findings are not contradictory with our enzyme activity measurements in minimally manipulated lung extracts.

Human liver, colon, small intestine and kidney have been shown to contain $20 \mathrm{~S}$ proteasomes with a mixed composition of standard and inducible immunosubunits (Baldovino et al. 2006, Visekruna et al. 2009, Guillaume et al. 2010). Furthermore, changes in the subunit composition of $20 \mathrm{~S}$ proteasomes under pathological conditions have been described in animal models and in patients (Barton et al. 2002, Visekruna et al. 2009, Zheng et al. 2012). Our findings demonstrate for the first time that all immuno-subunits and their constitutive counterparts are also detectable in extracts from donor and diseased lungs. Our Western blot experiments further suggest that both inducible immunosubunits and their constitutive counterparts form the $20 \mathrm{~S}$ core particle in lung extracts, which is in agreement with recent observations in lung tumor cell lines (Guillaume et al. 2010). Furthermore, the observation that multiple antibodies reacted with more than one band is consistent with the existence of multiple isoforms of most of the 20S proteasome subunits (Claverol et al. 2002, Chen et al. 2009).

The heterogeneity of the subunit distribution and the large variability among individual specimens that we detected could be explained by the exposure to inhaled particles and microbes throughout a person's lifetime (Nelson et al. 2000, Kwak et al. 2007, Kremer et al. 2010), which is specific to the individual and may have masked disease associated alterations.

Whereas we were unable to differentiate a disease specific pattern of the lung $20 \mathrm{~S}$ proteasome subunit composition, we cannot exclude that quantification of the subunit composition with more accurate and precise methods, such as subunit specific ELISAs, may be able to detect statistically significant differences between proteasomes from donor and diseased lungs. Our finding that the specific proteasome peptidase activity was similar in all extracts, however, argues against this possibility, because such differences would be expected to alter the specific enzyme activity (Eleuteri et al. 1997, Guillaume et al. 2010, Zu et al. 2010, Rodriguez et al. 2012, Zheng et al. 2012).

Limitations of this pilot study are the small sample size and the limited information about the donor and patient history. Therefore, we can currently not comment on the possible effects of other biological or 
behavioral factors, such as cigarette smoking or alpha1antitrypsin mutations (Novoradovskaya et al. 1998, van Rijt et al. 2012). Furthermore, we have utilized crude lung extracts for enzyme activity measurements; thus, proteasomes from non-lung cells, such as erythrocytes, and extracellular proteasomes may have confounded our findings. As erythrocyte proteasomes, however, do not contain 20S immuno-subunits and the concentrations of extracellular proteasomes are far below intracellular concentrations, such confounding effects appear negligible (Claverol et al. 2002, Chen et al. 2009, Majetschak et al. 2008b, Albright et al. 2009).

Several lines of evidence suggest that the proteasome is involved in the pathophysiology of organ fibrosis and proteasome inhibition has been shown to inhibit TGF- $\beta 1$ induced gene expression in primary human lung fibroblasts from healthy individuals and patients with IPF (Fineschi et al. 2006, Mutlu et al. 2012). Moreover, increases in proteasome peptidase activities have been detected in lung extracts several days after injury, which is known to lead to repair with fibrosis, and proteasome inhibition has been described to reduce lung fibrosis in some animal models (MatuteBello et al. 2008, Manning et al. 2009, Mutlu et al. 2012). As IPF and end-stage pulmonary sarcoidosis are characterized by a fibrotic remodeling of the lung, our findings support the concept that the higher content of lung proteasomes contributes to the pathophysiology of human fibrotic lung diseases. Further exploration of the proteasome as a drug target for these currently incurable diseases appears justified.

\section{Conflict of Interest}

There is no conflict of interest.

\section{Acknowledgement}

This study was supported in part by NIHT32 GM008750 (to RLG) and the Dr. Ralph and Marian Falk Medical Research Trust. The authors thank Jacqueline Romero for technical help. Parts of this research have been presented at the Clinical Congress of the American College of Surgeons 2011 ( $\mathrm{J}$ Am Coll Surg 213: 4-5, 2011).

\section{References}

ALBRIGHT JM, ROMERO J, SAINI V, SIXT SU, BIRD MD, KOVACS EJ, GAMELLI RL, PETERS J, MAJETSCHAK M: Proteasomes in human bronchoalveolar lavage fluid after burn and inhalation injury. J Burn Care Res 30: 948-956, 2009.

BAKER TA, GENG Q, ROMERO J, PICKEN MM, GAMELLI RL, MAJETSCHAK M: Prolongation of myocardial viability by proteasome inhibition during hypothermic organ preservation. Biochem Biophys Res Commun 401: 548-553, 2010.

BALDOVINO S, PICCININI M, ANSELMINO A, RAMONDETTI C, RINAUDO MT, COSTANZO P, SENA LM, ROCCATELLO D: Structural and functional properties of proteasomes purified from the human kidney. J Nephrol 19: 710-716, 2006.

BARTON LF, CRUZ M, RANGWALA R, DEEPE GS Jr, MONACO JJ: Regulation of immunoproteasome subunit expression in vivo following pathogenic fungal infection. $J$ Immunol 169: 3046-3052, 2002.

BAUMEISTER W, WALZ J, ZUHL F, SEEMULLER E: The proteasome: paradigm of a self-compartmentalizing protease. Cell 92: 367-380, 1998.

BODAS M, TRAN I, VIJ N: Therapeutic strategies to correct proteostasis-imbalance in chronic obstructive lung diseases. Curr Mol Med 12: 807-814, 2012.

BROOKS P, FUERTES G, MURRAY RZ, BOSE S, KNECHT E, RECHSTEINER MC, HENDIL KB, TANAKA K, DYSON J, RIVETT J: Subcellular localization of proteasomes and their regulatory complexes in mammalian cells. Biochem J 346: 155-161, 2000.

BUNN PA Jr: The potential role of proteasome inhibitors in the treatment of lung cancer. Clin Cancer Res 10: 4263s$4265 \mathrm{~s}, 2004$.

CHEN G, LUO Y, WANG X, ZHAO Z, LIU H, ZHANG H, LI Z: A relatively simple and economical protocol for proteomic analyses of human 20S proteasome: Compatible with both scaled-up and scaled-down purifications. Electrophoresis 30: 2422-2430, 2009. 
CLAVEROL S, BURLET-SCHILTZ O, GIRBAL-NEUHAUSER E, GAIRIN JE, MONSARRAT B: Mapping and structural dissection of human $20 \mathrm{~S}$ proteasome using proteomic approaches. Mol Cell Proteomics 1: 567-578, 2002.

DAHLMANN B, BECHER B, SOBEK A, EHLERS C, KOPP F, KUEHN L: In vitro activation of the 20 S proteasome. Enzyme Protein 47: 274-284, 1993.

ELEUTERI AM, KOHANSKI RA, CARDOZO C, ORLOWSKI M: Bovine spleen multicatalytic proteinase complex (proteasome). Replacement of X, Y, and Z subunits by LMP7, LMP2, and MECL1 and changes in properties and specificity. J Biol Chem 272: 11824-11831, 1997.

EYTAN E, ARMON T, HELLER H, BECK S, HERSHKO A: Ubiquitin C-terminal hydrolase activity associated with the 26 S protease complex. J Biol Chem 268: 4668-4674, 1993.

FINESCHI S, REITH W, GUERNE PA, DAYER JM, CHIZZOLINI C: Proteasome blockade exerts an antifibrotic activity by coordinately down-regulating type I collagen and tissue inhibitor of metalloproteinase-1 and upregulating metalloproteinase-1 production in human dermal fibroblasts. FASEB J 20: 562-564, 2006.

GALLASTEGUI N, GROLL M: The 26S proteasome: assembly and function of a destructive machine. Trends Biochem Sci 35: 634-642, 2010.

GENG Q, ROMERO J, SAINI V, BAKER TA, PICKEN MM, GAMELLI RL, MAJETSCHAK M: A subset of 26S proteasomes is activated at critically low ATP concentrations and contributes to myocardial injury during cold ischemia. Biochem Biophys Res Commun 390: 1136-1141, 2009.

GOMES AV, ZONG C, EDMONDSON RD, LI X, STEFANI E, ZHANG J, JONES RC, THYPARAMBIL S, WANG GW, QIAO X, BARDAG-GORCE F, PING P: Mapping the murine cardiac 26S proteasome complexes. Circ Res 99: 362-371, 2006.

GROLL M, HUBER R: Inhibitors of the eukaryotic 20S proteasome core particle: a structural approach. Biochim Biophys Acta 1695: 33-44, 2004.

GUILLAUME B, CHAPIRO J, STROOBANT V, COLAU D, VAN HOLLE B, PARVIZI G, BOUSQUET-DUBOUCH MP, THEATE I, PARMENTIER N, VAN DEN EYNDE BJ: Two abundant proteasome subtypes that uniquely process some antigens presented by HLA class I molecules. Proc Natl Acad Sci USA 107: 18599-18604, 2010.

HERSHKO A, CIECHANOVER A: The ubiquitin system. Annu Rev Biochem 67: 425-479, 1998.

KREMER M, HENN A, KOLB C, BASLER M, MOEBIUS J, GUILLAUME B, LEIST M, VAN DEN EYNDE BJ, GROETTRUP M: Reduced immunoproteasome formation and accumulation of immunoproteasomal precursors in the brains of lymphocytic choriomeningitis virus-infected mice. J Immunol 185: 5549-5560, 2010.

KWAK MK, HUANG B, CHANG H, KIM JA, KENSLER TW: Tissue specific increase of the catalytic subunits of the $26 \mathrm{~S}$ proteasome by indirect antioxidant dithiolethione in mice: enhanced activity for degradation of abnormal protein. Life Sci 80: 2411-2420, 2007.

LOWRY OH, ROSEBROUGH NJ, FARR AL, RANDALL RJ: Protein measurement with the Folin phenol reagent. J Biol Chem 193: 265-275, 1951.

MAJETSCHAK M, SORELL LT: Immunological methods to quantify and characterize proteasome complexes: development and application. J Immunol Methods 334: 91-103, 2008.

MAJETSCHAK M, PATEL MB, SORELL LT, LIOTTA C, LI S, PHAM SM: Cardiac proteasome dysfunction during cold ischemic storage and reperfusion in a murine heart transplantation model. Biochem Biophys Res Commun 365: 882-888, 2008a.

MAJETSCHAK M, PEREZ M, SORELL LT, LAM J, MALDONADO ME, HOFFMAN RW: Circulating 20S proteasome levels in patients with mixed connective tissue disease and systemic lupus erythematosus. Clin Vaccine Immunol 15: 1489-1493, $2008 \mathrm{~b}$.

MALHOTRA D, THIMMULAPPA R, VIJ N, NAVAS-ACIEN A, SUSSAN T, MERALI S, ZHANG L, KELSEN SG, MYERS A, WISE R, TUDER R, BISWAL S: Heightened endoplasmic reticulum stress in the lungs of patients with chronic obstructive pulmonary disease: the role of Nrf2-regulated proteasomal activity. Am J Respir Crit Care Med 180: 1196-1207, 2009. 
MANNING EW, PATEL MB, GARCIA-COVARRUBIAS L, RAHNEMAI-AZAR AA, PHAM SM, MAJETSCHAK M: Proteasome peptidase activities parallel histomorphological and functional consequences of ischemiareperfusion injury in the lung. Exp Lung Res 35: 284-295, 2009.

MATUTE-BELlO G, FREVERT CW, MARTIN TR: Animal models of acute lung injury. Am J Physiol 295: L379L399, 2008.

MENG L, MOHAN R, KWOK BH, ELOFSSON M, SIN N, CREWS CM: Epoxomicin, a potent and selective proteasome inhibitor, exhibits in vivo antiinflammatory activity. Proc Natl Acad Sci USA 96: 10403-10408, 1999.

MUTLU GM, BUDINGER GR, WU M, LAM AP, ZIRK A, RIVERA S, URICH D, CHIARELLA SE, GO LH, GHOSH AK, SELMAN M, PARDO A, VARGA J, KAMP DW, CHANDEL NS, SZNAJDER JI, JAIN M: Proteasomal inhibition after injury prevents fibrosis by modulating TGF-beta(1) signalling. Thorax 67: 139$146,2012$.

NELSON JE, LOUKISSA A, ALTSCHULlER-FELBERG C, MONACO JJ, FALLON JT, CARDOZO C: Up-regulation of the proteasome subunit LMP7 in tissues of endotoxemic rats. J Lab Clin Med 135: 324-331, 2000.

NOVORADOVSKAYA N, LEE J, YU ZX, FERRANS VJ, BRANTLY M: Inhibition of intracellular degradation increases secretion of a mutant form of alpha1-antitrypsin associated with profound deficiency. J Clin Invest 101: 2693-2701, 1998.

ORLOWSKI M: The multicatalytic proteinase complex, a major extralysosomal proteolytic system. Biochemistry 29: 10289-10297, 1990.

ORLOWSKI M, WILK S: Ubiquitin-independent proteolytic functions of the proteasome. Arch Biochem Biophys 415 : $1-5,2003$.

ROCK KL, GOLDBERG AL: Degradation of cell proteins and the generation of MHC class I-presented peptides. Annu Rev Immunol 17: 739-779, 1999.

RODRIGUEZ KA, EDREY YH, OSMULSKI P, GACZYNSKA M, BUFFENSTEIN R: Altered composition of liver proteasome assemblies contributes to enhanced proteasome activity in the exceptionally long-lived naked mole-rat. PLoS One 7: e35890, 2012.

SIJTS EJ, KLOETZEL PM: The role of the proteasome in the generation of MHC class I ligands and immune responses. Cell Mol Life Sci 68: 1491-1502, 2011.

TANAKA K, YOSHIMURA T, ICHIHARA A: Role of substrate in reversible activation of proteasomes (multiprotease complexes) by sodium dodecyl sulfate. J Biochem 106: 495-500, 1989.

VAN RIJT SH, KELLER IE, JOHN G, KOHSE K, YILDIRIM AÖ, EICKELBERG O, MEINERS S: Acute cigarette smoke exposure impairs proteasome function in the lung. Am J Physiol 303: L814-L823, 2012.

VISEKRUNA A, JOERIS T, SCHMIDT N, LAWRENZ M, RITZ JP, BUHR HJ, STEINHOFF U: Comparative expression analysis and characterization of $20 \mathrm{~S}$ proteasomes in human intestinal tissues: the proteasome pattern as diagnostic tool for IBD patients. Inflamm Bowel Dis 15: 526-533, 2009.

WEISS CH, BUDINGER GR, MUTLU GM, JAIN M: Proteasomal regulation of pulmonary fibrosis. Proc Am Thorac Soc 7: 77-83, 2010.

ZHAO J, WEI J, MIALKI RK, MALLAMPALLI DF, CHEN BB, COON T, ZOU C, MALLAMPALLI RK, ZHAO Y: F-box protein FBXL19-mediated ubiquitination and degradation of the receptor for IL-33 limits pulmonary inflammation. Nat Immunol 13: 651-658, 2012.

ZHENG J, DASGUPTA A, BIZZOZERO OA: Changes in 20S subunit composition are largely responsible for altered proteasomal activities in experimental autoimmune encephalomyelitis. J Neurochem 121: 486-494, 2012.

ZU L, BEDJA D, FOX-TALBOT K, GABRIELSON KL, VAN KAER L, BECKER LC, CAI ZP: Evidence for a role of immunoproteasomes in regulating cardiac muscle mass in diabetic mice. J Mol Cell Cardiol 49: 5-15, 2010. 